\title{
Population awareness of risks related to medicinal product use in Vientiane Capital, Lao PDR: a cross-sectional study for public health improvement in low and middle income countries
}

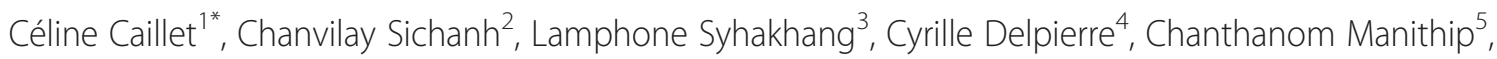
Mayfong Mayxay ${ }^{6,7}$, Maryse Lapeyre-Mestre ${ }^{1}$, Paul N Newton ${ }^{2,6,8}$ and Anne Roussin ${ }^{1}$

\begin{abstract}
Background: While essential medicines have been made more available in all but the most remote areas in low and middle income countries (L/MICs) over the past years, inappropriate and incorrect use of good quality medicines remains a key impediment for public health. In addition, as medicines have a potential to cause harm (medicine risks), adequate awareness by medicine users of the risks of adverse reactions is essential, especially as self-medication is common in L/MICs. This study aimed to investigate the awareness of Lao residents regarding medicine risks in Vientiane Capital, Lao People's Democratic Republic.
\end{abstract}

Methods: Face-to-face interviews using structured questionnaires of 144 residents older than 16 years were carried out in 12 randomly selected villages out of the 146 villages of Vientiane Capital with at least one health facility.

Results: The respondents were mainly (85.0 \%) the heads of households or their husband/spouse . The majority of the respondents were unaware (61.8\%) of medicine risks. Compared to residents living in the urban district of Xaysetha, living in peri-urban and even more in rural areas were identified as factors associated with being unaware of medicine risks [adjusted odds ratio $(\mathrm{aOR})=3.3,95 \%$ Confidence Interval $(\mathrm{Cl})=1.1-9.4])$ and $\mathrm{aOR}=7.5(95 \% \mathrm{Cl}=$ 2.3-24.2), respectively]. In addition, more than half of the respondents had never heard of poor quality medicines, with a higher rate in rural/peri-urban compared to urban districts ( $55.6 \%$ vs $38.9 \%$, respectively, $p=0.02$ ). Finally, approximately one third of all respondents thought that traditional medicines could not cause harm.

Conclusions: Overall, these results suggest a lack of awareness about medicinal product risks. Differences according to the place of residence are apparent and could be partly explained by a lower level of training of healthcare providers in contact with the population in the rural districts in particular. Communication on medicinal product risks to patients through well-trained healthcare providers could probably make a valuable contribution towards the appropriate use of medicines in L/MICs.

Keywords: Lao PDR, Low- and middle-income countries, Public health, Population, Awareness, Safety, Medicinal products

\footnotetext{
*Correspondence: celine.caillet@univ-tlse3.fr

${ }^{1}$ Faculté de Médecine, Equipe de Pharmacoépidémiologie UMR 1027

INSERM-Université de Toulouse III, Service de Pharmacologie Médicale et

Clinique, Centre Hospitalier Universitaire de Toulouse, 37 allées Jules Guesde,

31000 Toulouse, France

Full list of author information is available at the end of the article
} 


\section{Background}

Over the past 20 years, the rapid expansion of health markets, especially in low and middle income countries (L/MICs) in Asia and in Africa, has made many medicines available in all but the most remote areas [1]. This growing market, although providing pharmacological treatments to many patients, has raised problems of drug safety associated with inappropriate and incorrect use of medicines. The World Health Organization (WHO) estimates that more than $50 \%$ of all medicines are prescribed, dispensed or sold inappropriately and that half of all patients fail to take medicines correctly [2].

In L/MICs countries, medicine users themselves are key actors for an appropriate and correct use of medicines. Indeed, self-medication is a common practice, partly because most medicines are available without any prescription [3]. Moreover, people commonly use traditional medicines for which safety is relatively unknown $[4,5]$. Finally, people in L/MICs countries are more and more exposed to the growing market of poor quality medicines [6]. Consequently, the threat of adverse drug reactions (ADRs) is a major issue in these countries.

In a survey performed in Zimbabwe, $65 \%$ of the interviewees (adults members of households) were unaware of over-the-counter (OTC) medicine risks [7]. Developing people's awareness of the potential harmful effects of medicinal products may be particularly relevant to improve their appropriate and correct use.

Lao People's Democratic Republic (Lao PDR) is a lowermiddle income country in South-East Asia. Although efforts have been made to improve the use of medicines since the adoption of the National Drug Policy in 1993 [8], some important issues remain, such as the low quality of private pharmacy services [9], common self-medication $[10,11]$, inappropriate prescribing and dispensing of medicines in public health facilities [12], and the existence of poor quality medicines in the market [13].

The aim of this study was to investigate the awareness of the population on medicine risks in Vientiane Capital, Lao PDR. In addition, we aimed to study the awareness of the population on traditional medicine risks and on the existence of poor quality medicines.

\section{Methods}

\section{Study population}

This cross-sectional study was conducted between August and November 2012 in Vientiane Capital. Vientiane Capital is composed of nine districts and 483 villages and had an estimated population of 797,130 inhabitants in 2012 [14].

With the aim to get a representative study population of Vientiane Capital districts, two urban districts (Xaysetha and Sikhottabong) were randomly selected among the four urban ones, one (Naxaithong) among the three peri-urban districts and one (Sangthong) among the two rural districts (simple random samplings). Differentiation of the districts into urban, peri-urban and rural was based on previous publications $[15,16]$.

In a previous study in Zimbabwe, the prevalence of citizens unaware of the potential harm induced by OTC drugs was $65 \%$ [7]. Based on this prevalence, we aimed to include 87 to 350 villagers, allowing a precision between 5 and $10 \%$. This interval was conditioned by the lack of availability of skilled interviewers with medical or pharmaceutical degree. We calculated that three interviewers could interview 10 villagers per village and per day. With an estimated rate of refusal of $20 \%, 12$ villagers were thus included per village. Three villages per district (this number was chosen for convenience) were randomly selected by simple sampling among the villages with at least one health facility (health centre, hospital, private clinic or private pharmacy), representing $8.2 \%(n=12)$ of all the eligible villages $(n=146)$ in the four surveyed districts.

In the villages where a list of the households was available $(n=8), 12$ households were selected by systematic random sampling. Systematic sampling involves a random start and then proceeds with the selection of every $k$ th element from then onwards [17]. For each village, $k$ was calculated as the total number of households divided by 12 . In the other villages $(n=4)$ a list of 'clusters of households' was provided by the head of the village. From this list, 12 clusters were selected by systematic sampling and in each cluster one household was then chosen at the time of the survey by the research team. The head of the household or his/her wife/husband was interviewed if available at the time of the visit. When s/ he was not available, another member of the household was interviewed ( $\geq 16$ years old).

\section{Questionnaire and data collection}

The questionnaire was developed for the purpose of the study. It was structured into four sections related to: sociodemography, medicinal products use, awareness of medicinal product risks (including traditional medicines, modern medicines and poor quality medicines) and experience of ADR (Table 1).

Most of the questions were closed-ended questions (yes/ no or yes/no/do not know) and a few were open-ended. The open-ended questions were read without mentioning any predetermined answers, and the information collected was coded based on identified thematic areas.

Two questions were used to define the awareness of modern medicine risks. The first one was 'Have you ever heard what an ADR is?'. In addition, in order not to underestimate the awareness of the population, a second question was added 'Do you think that modern medicines can be harmful in case of normal use and normal 
Table 1 Questionnaire for survey of population awareness of risks related to medicinal products use

A. Sociodemographic characteristics
1. Gender
2. Age
3. Status in the household

\section{Occupation}

5. Monthly household income (Lao kip)

6. Religion

7. Level of education

8. Can you read?

9. Do you have easy access to internet?

B. Medicinal product use

1. Have you ever consumed modern medicine(s)?

Was the last time during the last 12 months?

If yes, name(s) of the medicine(s) and its (their) indication(s)

2. Have you ever consumed traditional medicine(s)?

Was the last time during the last 12 months?

If yes, name(s) of the medicine(s) and its (their) indication(s)

C. Awareness of medicinal product risks

1. Do you think that modern medicines can be harmful in case of normal use and normal doses?

Comment(s)

2. Do you think that modern medicines can be harmful in case of overdosage?

3. Do you think that traditional medicines can be harmful in case of normal use and normal doses?

4. Do you think that traditional medicines can be harmful in case of overdosage?

5. Have you ever heard what an adverse drug reaction is? Comment(s)

6 . Have you ever heard of poor quality medicines?

If yes, do you think that poor quality medicines can be harmful?

Comment(s)

7. Where have you heard of poor quality medicines?

\section{Answers}

o Male o Female

\begin{tabular}{|c|c|c|}
\hline $\begin{array}{l}\text { o Head of } \\
\text { household }\end{array}$ & $\begin{array}{l}\text { o Spouse or husband } \\
\text { head of household }\end{array}$ & \\
\hline \multicolumn{3}{|c|}{ o Other, specify ___ } \\
\hline o Housekeeper & o Farmer & o Other job \\
\hline o Retired/disabled & o Student & \\
\hline $0 \leq 1000000$ & $0>1000000$ & \\
\hline $\begin{array}{ll}\circ & \text { O } \\
\text { Buddhism } & \text { Animism }\end{array}$ & o Other, specify & \\
\hline $\begin{array}{l}\text { o Secondary school } \\
\text { or higher }\end{array}$ & $\begin{array}{l}\text { o Primary school or no } \\
\text { education }\end{array}$ & \\
\hline o Yes & o No & \\
\hline o Yes & o No & \\
\hline o Yes & o No & \\
\hline o Yes & o No & \\
\hline o Yes & o No & \\
\hline o Yes & o No & \\
\hline
\end{tabular}

o Yes o No o Do not know
o Yes
o No
o Do not know

o No

o Do not know

o Yes o No o Do not know

o Yes o No

o Yes o No

o Yes o No o Do not know

o Healthcare o Magazine, journal providers

o TV o Relative, friend o Other, specify

D. Experience of adverse drug reaction

1. Have you (or one of your relative) ever taken a medicine (modern medicine, traditional medicine) that made you feel worse?

o Yes

o No

If yes, please describe the reaction and the name(s) of the medicine(s)

A Pharmacovigilance system is a 'drug monitoring' system. This system works through spontaneous reporting of drug-related problems by health care professionals and patients.

2. Would you agree to notify a drug-related problem to the national

o Yes

o No pharmacovigilance center? 
doses?'. This latter was adapted from another study [7]. In order to verify their understandings of these two questions, the positive respondents were invited to give comments.

A negative answer to the first question (ADR) and a negative or a 'do not know' answer to the second one were the criteria to consider a villager as unaware of medicine risks.

The questionnaire was developed in English and translated into Lao by a Laotian pharmacist with strong background of English practice. The technical words were checked by two Laotian pharmacists specialized in public health. The questionnaire was then back-translated into English by a Lao medical doctor with a Tropical and International Health degree to make sure the first translation was accurate. After translation and backtranslation, no discrepancies for the questions used for the measures of the outcome were highlighted. We piloted the questionnaire with four villagers (heads of household or their spouse/husband) living in Vientiane to assess understanding and ease of completion. The respondents to the pilot survey were asked to tell if all the words were understood and they were also asked to explain in details the choices of their answers, with a particular attention to the questions of the Section C and D.

The questionnaires were administered by face-to-face interviews by three trained physicians using local language (i.e. Lao), either in the office of the head of the village (in two villages), at the temple of the village (in one village), or within the households (in nine villages).

\section{Data analysis}

Characteristics of those unaware versus aware of medicine risks were compared using $x^{2}$ tests when all expected counts were above five, or otherwise with Fisher's exact tests. T-tests were used to compare quantitative characteristics if the equality of the variances was confirmed by F-tests. If variances were not equal, Wilcoxon tests were used.

To identify factors associated to the unawareness of medicine risks, logistic regression was performed. The following socio-economic characteristics were tested: gender, age, educational level, district, monthly household income, status within the household, occupation, ability to read and access to internet. The variables with a $p$-value $<0.20$ after univariate analysis were entered into a multivariate logistic regression model.

The goodness of fit of the final model was assessed using the Hosmer and Lemeshow test. The results are presented as odds-ratio (OR) or adjusted odds ratios (aOR) and their $95 \%$ confidence intervals (CI). Data analysis was carried out using SAS $^{\circ} 9.3$ software (SAS Inst., Cary, North Carolina, USA). The level of significance was set at 0.05 (two-sided).

\section{Ethical approval}

Written informed consent was obtained from all participants. Ethical clearance for the study was granted by the Ethics Committee of the University of Health Sciences, Ministry of Health of Laos.

\section{Results \\ Respondent characteristics}

A total of 144 Lao citizens were solicited and all consented. An equal number of respondents in each selected district $(n=36)$ were included. More women ( $n$ $=108)$ than men $(n=36)$ were included and the mean age was 45.1 (SD 12.5) years old. One-third of all respondents $(n=47)$ were the heads of the household, with a majority of men $(n=32)$. Half $(n=74)$ were their spouses.

A total of 89 [61.8\% (95\% CI $=53.8-69.8)]$ respondents were unaware of modern medicine risks (Table 2). Respondents being unaware tended to have a lower level of education than those being aware (55.1 vs $34.6 \%$, $p=0.03)$. There were differences according to the district $(p<0.001)$. Respondents being unaware tended to live more in the rural district of Sangthong (33.7 vs $10.9 \%, p<0.01$ respectively) and less in the urban district of Xaysetha than those being aware (15.7 vs $40.0 \%$, $p<0.01$ respectively). The proportions of respondents living in Sikhottabong (urban) or in Naxaithong (periurban) were not statistically different between the respondents being aware and unaware.

\section{Medicinal product use}

All the respondents claimed to have used a modern medicine and $87(60.4 \%)$ a traditional medicine during their lifetime. One-hundred and two (70.8 \%) respondents had used at least one medicine (modern or traditional) within the last 12 months. Fifty-one (50.0\%) of them could not give the names of the last modern medicines used within the previous 12 months (Table 3). The main indications of these unidentified modern medicines were pain $(n=17)$, fever $(n=6)$, diabetes $(n=4)$, allergy $(n=3)$, cough $(n=3)$, contraception $(n=2)$, hypertension $(n=2)$ and hypercholesterolemia $(n=2)$. Among the modern medicines that the respondents were able to name, analgesics and vitamins were the most frequently used. The analgesics were paracetamol or paracetamol in combination with antihistamine and sympathomimetic agents $(n=14)$, non-steroidal anti-inflammatory drugs $(n$ $=3)$, and metamizole $(n=1)$.

None of the 15 respondents could give a name for the traditional medicines. However, most could give a description of the part of the plant used [(e.g. 'leaves of a tree' $(n=3)$ or 'roots of a tree' $(n=6)$ ] and its indication [mainly pain $(n=5)$, diabetes $(n=2)$ and gastritis $(n=2)]$. 
Table 2 Socio-demographic characteristics of the respondents ( $N=144)$ according to the awareness of medicine risks

\begin{tabular}{|c|c|c|c|}
\hline & $\begin{array}{l}\text { Aware of } \\
\text { medicine risks } \\
\mathrm{n}(\%)\end{array}$ & $\begin{array}{l}\text { Unaware of } \\
\text { medicine risks } \\
\mathrm{n}(\%)\end{array}$ & $p$-value* \\
\hline Total & $55(38.2)$ & $89(61.8)$ & \\
\hline Age (years) & & & 0.07 \\
\hline Mean \pm SD & $42.7 \pm 10.6$ & $46.5 \pm 13.4$ & \\
\hline Gender & & & 0.24 \\
\hline Male & $17(30.9)$ & $19(21.4)$ & \\
\hline Female & $38(69.1)$ & 70 (78.6) & \\
\hline Status in the household & & & 0.76 \\
\hline Head of household & $16(29.1)$ & $31(34.8)$ & \\
\hline $\begin{array}{l}\text { Husband/spouse of the } \\
\text { head of household }\end{array}$ & $29(52.7)$ & $45(50.6)$ & \\
\hline Other & $10(18.2)$ & $13(14.6)$ & \\
\hline Occupation & & & 0.10 \\
\hline $\begin{array}{l}\text { In employment } \\
\text { (except farmers) }\end{array}$ & $35(63.6)$ & $42(47.2)$ & \\
\hline Housekeeper & $13(23.6)$ & $24(27.0)$ & \\
\hline Farmer & $7(12.7)$ & $23(25.8)$ & \\
\hline Religion & & & 0.52 \\
\hline Buddhism & $55(100.0)$ & $87(97.8)$ & \\
\hline Animism & 0 & $2(2.3)$ & \\
\hline $\begin{array}{l}\text { Monthly household } \\
\text { income (Lao Kip) }\end{array}$ & & & 0.13 \\
\hline$>1,000,000$ & $7(13.0)$ & $21(24.1)$ & \\
\hline$\leq 1,000,000$ & $47(87.0)$ & $66(75.9)$ & \\
\hline Level of education & & & 0.03 \\
\hline Secondary or higher & $36(65.5)$ & $40(44.9)$ & \\
\hline $\begin{array}{l}\text { No education or primary } \\
\text { school }\end{array}$ & 19 (34.6) & $49(55.1)$ & \\
\hline Can read & & & 0.74 \\
\hline Yes & $52(94.6)$ & $82(92.1)$ & \\
\hline No & $3(5.5)$ & $7(7.9)$ & \\
\hline Access to internet & & & 0.08 \\
\hline Yes & $8(14.6)$ & $5(5.6)$ & \\
\hline No & $47(85.5)$ & $84(94.4)$ & \\
\hline District & & & 0.001 \\
\hline Xaysetha & $22(40.0)$ & $14(15.7)$ & \\
\hline Sikhottabong & $15(27.3)$ & 21 (23.6) & \\
\hline Naxaithong & $12(21.8)$ & $24(27.0)$ & \\
\hline Sangthong & $6(10.9)$ & $30(33.7)$ & \\
\hline
\end{tabular}

${ }^{*}{ }^{2}$, Fisher's tests (qualitative characteristics) or t-test (quantitative characteristics)

Factors potentially associated with being unaware vs being aware of medicine risks

Occupation was not included in the multivariate regression model because of a strong collinearity with the
Table 3 Last medicines used within the previous 12 months by the 102 respondents

\begin{tabular}{ll}
\hline Medicines & $\mathrm{n}(\%)$ \\
\hline Unknown/unidentified & $51(50.0)$ \\
Analgesics & $18(17.6)$ \\
Vitamins/minerals & $14(13.7)$ \\
Traditional medicines & $13(12.7)$ \\
Anti-infectious & $10(9.8)$ \\
Medicines of gastro-intestinal disorders & $8(7.8)$ \\
Cardiovascular medicines & $5(4.9)$ \\
Antidiabetics & $5(4.9)$ \\
Other & $2(2.0)$ \\
\hline
\end{tabular}

district. Indeed, there were significantly more farmers in the rural and peri-urban districts as compared to urban ones ( $38.6 \%$ and $36.1 \%$ vs $4.2 \%$, respectively, $p<0.01$ ).

In the multivariate logistic regression model, the district was the only significant variable potentially associated with an increased risk of being unaware of risks related to medicine use. Compared to the respondents of the urban district of Xaysetha, the respondents in the peri-urban (Naxaithong) and even more in the rural district (Sangthong) were more likely to be unaware of medicine risks $[\mathrm{aOR}=3.3,(95 \% \mathrm{CI}=1.1-9.4)$ and $\mathrm{aOR}=7.5$ $(95 \% \mathrm{CI}=2.3-24.2)$, respectively] (Table 4). The respondents in the rural district were also more likely to be unaware of medicine risks compared to those living in the urban district of Sikhottabong $[\mathrm{aOR}=4.5(95 \% \mathrm{CI}=$ 1.3-15.1)] but no statistical differences were observed between the respondents in Sikhottabong and those in the peri-urban district of Naxaithong [aOR $=1.9(95 \%$ $\mathrm{CI}=0.7-5.7)]$.

\section{Awareness of medicinal product safety}

Among the 55 respondents who were qualified as aware of modern medicine risks, 53 (96.4 \%) had heard what an ADR is. These respondents gave examples of symptoms of adverse reactions. The most commonly quoted were allergic and gastro-intestinal symptoms. Sometimes the respondents associated the culprit medicine to the symptom (e.g.: 'ampicillin can cause allergy'). Some respondents also tried to define what an ADR is (ex: 'it is when new symptoms appear when you take a medicine'). Of these 53 respondents, a majority $(n=45,84.9 \%)$ said that modern medicines are potentially harmful in overdosage, but only five $(9.4 \%)$ believed that they can be harmful at recommended doses.

Regarding traditional medicines, 83 (57.7 \%) participants believed that they are not potentially harmful with normal doses and with normal use, and about half of 
Table 4 Factors influencing the awareness of the population regarding medicines risks: 'unaware' vs 'aware'. Results of univariate and multivariate analysis

\begin{tabular}{|c|c|c|c|c|}
\hline \multirow[b]{2}{*}{ Variables } & \multicolumn{2}{|c|}{$\underline{\text { Univariate analysis }}$} & \multicolumn{2}{|l|}{ Multivariate analysis } \\
\hline & OR $(95 \% \mathrm{Cl})$ & $\overline{p \text {-value }}$ & Adjusted OR (95\% Cl) & $p$-value \\
\hline Age group (years) & & 0.10 & & 0.11 \\
\hline$\leq 40$ & 1 & & 1 & \\
\hline$[40-50]$ & $0.9(0.4-2.0)$ & & $0.8(0.3-2.0)$ & \\
\hline$>50$ & $2.3(0.9-5.5)$ & & $2.3(0.8-6.7)$ & \\
\hline Gender & & 0.21 & & \\
\hline Male & 1 & & & \\
\hline Female & $1.6(0.8-3.5)$ & & & \\
\hline Status in the household & & 0.72 & & \\
\hline Head of household & 1 & & & \\
\hline Husband/spouse of the head of household & $0.8(0.4-1.7)$ & & & \\
\hline Other & $0.7(0.2-1.9)$ & & & \\
\hline Occupation & & 0.10 & & \\
\hline In employment (except farmer) & 1 & & & \\
\hline Housekeeper & $1.5(0.7-3.5)$ & & & \\
\hline Farmer & $2.7(1.1-7.1)$ & & & \\
\hline Religion & & 0.99 & & \\
\hline Buddhism & 1 & & & \\
\hline Animism & N/A & & & \\
\hline Monthly household income (Lao Kip) & & 0.11 & & 0.06 \\
\hline$>1,000,000$ & 1 & & 1 & \\
\hline$\leq 1,000,000$ & $2.1(0.8-5.4)$ & & $2.8(1.0-8.1)$ & \\
\hline Level of education & & 0.02 & & 0.56 \\
\hline Secondary or higher & 1 & & 1 & \\
\hline Primary school or no education & $2.3(1.2-4.7)$ & & $1.3(0.6-2.9)$ & \\
\hline Ability to read & & 0.58 & & \\
\hline Yes & 1 & & & \\
\hline No & $1.5(0.4-6.0)$ & & & \\
\hline Access to internet & & 0.08 & & 0.22 \\
\hline Yes & 1 & & 1 & \\
\hline No & $2.9(0.9-9.2)$ & & $2.3(0.6-8.5)$ & \\
\hline District & & $<0.01$ & & $<0.01$ \\
\hline Xaysetha & 1 & & 1 & \\
\hline Sikhottabong & $2.2(0.9-5.6)$ & & $1.7(0.6-4.8)$ & \\
\hline Naxaithong & $3.1(1.2-8.2)$ & & $3.3(1.1-9.4)$ & \\
\hline Sangthong & $7.9(2.6-23.7)$ & & $7.5(2.3-24.2)$ & \\
\hline
\end{tabular}

$O R$, odds-ratio; $C l$, confidence interval

The occupation factor was not included in the multivariate model because of its strong collinearity with the district localization

them $(\mathrm{n}=39)$, representing $27.1 \%$ of all the participants, thought that they are safe in overdosage. In addition, 46 $(31.9 \%)$ and $54(37.5 \%)$ respondents had no opinion on the potential noxiousness of traditional medicines in case of normal use and in overdosage, respectively.

\section{Awareness of the existence of poor quality medicines}

One half $(n=68,47.2 \%)$ of the respondents had heard of poor quality medicines, mainly through media (TV, radio, papers; $n=41,60.3 \%$ ) or through relatives/friends ( $n=16,23.5 \%)$. Those living in peri-urban/rural districts 
were significantly less aware of their existence in comparison to those in urban districts $(38.9 \%$ vs $55.6 \%$, respectively, $p=0.02$ ). In response to the question 'Do you think that poor quality medicines can be harmful?', most of the respondents $(n=59,86.8 \%)$ answered yes and 8 $(11.8 \%)$ had no opinion. Respondents were invited to comment on this latter question. Among the respondents who gave a comment $(n=40), 18(45 \%)$ expressed concerns regarding the risk of inefficacy of the poor quality medicines, $11(27.5 \%)$ about the potential occurrence of ADRs (e.g. 'harmful for the liver', 'harmful for the kidney') and 6 (15\%) expressed both concerns of inefficacy and potential occurrence of ADRs.

\section{Experience of adverse reaction to modern or traditional medicines}

Fifty-two $(36.1 \%)$ respondents claimed to have encountered a medicine that 'made them or their relative feel worse, most of them being aware of medicine risks $(60 \%$ versus $21 \%$ being unaware, $p<0.001)$. All described the reaction observed, but only half $(n=28)$ could give the name or the pharmacological class of the medicine involved, an antibiotic being involved in 18 cases (64.3\%). Symptoms of allergy such as 'rash', 'shock', 'dyspnea' or 'oedema' were described by 35 (67.3\%) respondents among whom five were serious adverse reactions (e.g. angioneurotic oedema). Forty percent of the cases of allergy involved antibiotics $(n=14)$, one case involved the 'leaves of a tree' and 15 (42.9 \%) respondents did not know the name of the medicine(s) involved. Gastrointestinal symptoms (9 cases, $17.3 \%$ ) and general symptoms such as 'fatigue' or 'dizziness' (15 cases, $28.9 \%)$ were also noted. A total of 140 (97.2\%) respondents would agree to notify an ADR to the concerned authority in the future.

\section{Discussion}

In this population-based study, the majority of the respondents were unaware of modern medicine risks. Most of the respondents qualified as aware had an inadequate awareness since most thought that modern medicines can be harmful only in overdosage. As for modern medicines, the awareness of traditional medicine risks was limited. Half of the participants were not aware of the existence of poor quality medicines in the market.

The median age (47 years old) of our population is higher than that of the population at national level since $75 \%$ of people were aged between 15 and 45 years old in 2005 [18]. More women than men were interviewed mainly because interviews were performed during working hours. Nevertheless, even if our population does not strictly represent the general population of lao adults, $85 \%$ of the respondents were the heads of household or their husband/spouse, who play an important role in healthcare choices for the whole family in L/MICs [19-21]. No citizen refused to participate in the study. Government staffs have a strong influence on citizens in the Lao PDR. The $100 \%$ response rate can thus result from the first contact of the citizens that was made by the head of the village or his mandated assistant. Whereas these latter were present during some interviews, they agreed to stay apart. However, when the interviews were performed in the households it was difficult to maintain strict confidentiality, as other family members or neighbours sometimes came to listen.

In our survey, only one-fourth of the population is rural. As $71 \%$ of the population of the Lao PDR lived in rural areas in 2007/2008 [22], we can reasonably assume that the awareness of the general population of Lao PDR regarding the issue of medicinal product risks is lower than that observed in our study. This is highlighted by the significant differences of awareness observed between the districts, respondents in the rural district having a higher risk of being unaware than those in urban districts. Further data $[18,23]$ have shown that the distribution of health facilities was different according to the districts. Private clinics - run by medical doctors with university degree -, and class I community pharmacies - run by pharmacists with university degree -, are more prevalent in the urban districts of Xaysetha (84.1 and 40.0/100,000 inhabitants, respectively) and Sikhottabong (44.0 and 13.0/ 100,000 inhabitants respectively) than in the peri-urban district of Naxaithong (30.8 and 1.7/100,000 inhabitants, respectively) and in the rural district of Sangthong (24.8 and 4.1/100,000 inhabitants, respectively). Therefore, we suggest that whereas people in rural areas have access to health facilities, urban residents have a better opportunity to receive information from healthcare providers of higher level of training. Whereas respondents in the urban district of Sikhottabong have a significant higher awareness than those in the rural district of Sangthong, there were no differences with those in the peri-urban district of Naxaithong. This could be explained by the distribution of health facilities in Sikhottabong that is in between that of the peri-urban district of Naxaithong and of the urban district of Xaysetha. In addition, as suggested by Syhakhang et al. [16], people in urban areas may have better opportunity to receive information on medicines from the regulatory authority. More investigations are needed to assess other potential factors that might explain the differences between the districts.

In the absence of validated questionnaire to assess the awareness of the population on medicine risks when they are used with normal doses, our questionnaire was developed for the purpose of this study. While its reliability and validity have not been tested, the questionnaire 
was submitted to four experts in public health, epidemiology and pharmacology for an opinion, before being translated into Lao. The term ADR is defined by the $\mathrm{WHO}$ as "a response to a drug which is noxious and unintended and which occurs at doses normally used in humans"[24]. It is used for communication on drug safety in validated sources of information on medicines (i.e. summary of products characteristics and leaflets). However, when this term has never been heard by a villager, it does not necessarily mean that he is not aware of medicine risks. We thus combined this question to a second one ('Do you think that modern medicines can be harmful in case of normal use and normal doses?') to define our outcome of interest.

We observed that even when they were qualified as aware of medicine risks, the large majority of our respondents think that modern medicines are potentially harmful only in overdosage. In addition, the majority of the respondents in our study considers traditional medicines as safe or has no opinion, even in overdosage. Therefore, strategies to raise awareness of the population on drug safety, without scaring patients from using medicinal products are needed, with special attention to rural areas. This is particularly important in a country where most medicines, even the most harmful, are readily available OTC. Mass media campaigns have previously shown promising results in health promotion in $\mathrm{L} /$ MICs [25, 26]. Adequate key messages on drug safety, for example targeting medicinal products commonly involved in ADRs could be relevant. For this purpose, drug safety data in the Lao PDR are needed.

Half of our respondents had never heard of poor quality medicines. Although efforts made by the government since the implementation of the National Drug Policy [8] have allowed reduction in the proportion of poor quality medicines in the market [27], the threat is still real [13]. Most of the people being aware of poor quality medicines had been informed through media in our study. Initiatives to raise awareness of the population such as the 'Mekong Cartoon Contest' in 2011 ("Beware of counterfeiting, danger is calling!") with online diffusion of the cartoons [28], need to be continued.

Half of our participants could not name the last medicines used within the last year. This can be due to recall bias, illiteracy concerns or non-adherence to prescribed medications (with regard to chronic diseases medications). This could also result from a lack of identification of medicines, as previously observed in two studies in which half of the medicines sold in private or public pharmacies had no label $[9,29]$. As accepted important sources of information on drug use and safety [30], the provision of labels and package inserts should be endorsed. It should be mentioned that a new article (2012) of the Laotian law on drug and medical products states that medicine users should receive clear and complete information from medicines suppliers. However, package inserts are often written in medical jargon and too many information is generally provided. They are thus difficult to understand [31]. When printed in foreign languages, they can be incomprehensible for patients, especially in rural areas [7]. Distributed by pharmacists and other health professionals, well-adapted model sets of minimum information developed in a way that is relevant to each population - e.g. using regional languages and illustrations [32] - have previously shown good effectiveness [33, 34]. The best effects on patients knowledge are evident when both written and oral information on medicines are provided [35]. In a previous study by Stenson et al. [9], oral information were not transmitted for more than half of medicines sold in laotian pharmacies of low level (class III). Engaging all healthcare professionals in providing adequate oral information is essential - especially in the context of high illiteracy - , not only to improve patients' understanding of their medication, but also to build trustworthy health system [36-38]. Enhancing the training of pharmacist and medical students on drug safety communication seems necessary in the Lao PDR.

In line with the efforts to improve the use of medicines, the Lao PDR has recently (2013) become an associate member of the WHO Programme for International Drug Monitoring [39]. Drug safety monitoring requires the involvement of healthcare professionals. In addition, central, provincial or district level drug information centers for patients who seek information on medicines could help transforming medicine users from passive recipients to active partners [40-42]. In remote areas, community health workers or community leaders have proved highly effectiveness in promoting health [43, 44] and could constitute mediators between the population and a drug information center. At last, mobile technologies and web-based systems have recently proved good performance in health care processes in Asia [45, 46].

\section{Conclusion}

We have demonstrated concerns about the awareness of the risks of medicinal products among the population of Vientiane Capital. Differences according to the place of residence are apparent and could be partly explained by a lower level of training of healthcare providers in contact with the population in the rural districts in particular. The most important recommendation would be to invest more in education and information about these risks for the population. This could make a valuable contribution towards the improvement of the appropriate and correct use of medicines, and thus towards drug safety, in Lao PDR and in L/MICs in general. 


\section{Abbreviations}

L/MICs: Low- and middle-income countries; ADRs: Adverse drug reactions: PDR: People's Democratic Republic; WHO: World Health Organization; OR: Odds ratio; OTC: Over-the-counter.

\section{Competing interests}

The authors declare that they have no competing interests.

\section{Authors' contributions}

$C C, C D, L S, C M, M L M, M M, P N N$ and $A R$ were involved in the design of this study and conceived the idea for the article. CC and CS were responsible for the data collection. CC performed the data analysis, wrote the first draft of the paper and coordinated contributions from other co-authors. All authors read and approved the manuscript.

\section{Acknowledgements}

This work was performed in collaboration with the Pierre Fabre Foundation Without its support, this research would not have been implemented. We are very grateful to the Directors of Mahosot Hospital and Dr Rattanaphone Phetsouvanh and staff of the Microbiology Laboratory. We also acknowledge Dr Valy Keoluangkhot and Dr Naphaphone Phalivong for their help for the translations of the questionnaires.

\section{Author details}

${ }^{1}$ Faculté de Médecine, Equipe de Pharmacoépidémiologie UMR 1027 INSERM-Université de Toulouse III, Service de Pharmacologie Médicale et Clinique, Centre Hospitalier Universitaire de Toulouse, 37 allées Jules Guesde, 31000 Toulouse, France. ${ }^{2}$ WorldWide Antimalarial Resistance Network, University of Oxford, Wellington Square, OX1 2JD Oxford, UK. ${ }^{3}$ Food and Drug Department, Ministry of Health, Simuang Road, Vientiane Capital, Lao People's Democratic Republic. ${ }^{4}$ Faculté de Médecine, Cancer et maladies chroniques, UMR1027 INSERM- Université de Toulouse III, 37 Allées Jules Gusede, 31000 Toulouse, France. ${ }^{5}$ Faculty of Pharmacy, University of Health Sciences, P.O.Box 7444Samsenthai Road, Vientiane, Lao People's Democratic Republic. ' Lao-Oxford-Mahosot Hospital-Wellcome Trust Research Unit, Microbiology Laboratory, Mahosot Hospital, FaNgum Rd, Vientiane, Lao People's Democratic Republic. ${ }^{7}$ Faculty of Postgraduate Studies, University of Health Sciences, P.O.Box 7444Samsenthai Road, Vientiane, Lao People's Democratic Republic. ${ }^{8}$ Centre for Tropical Medicine and Global Health, Nuffield Department of Medicine, Churchill Hospital, University of Oxford, Wellington Square, OX1 2JD Oxford, UK.

\section{Received: 27 October 2014 Accepted: 18 June 2015}

Published online: 27 June 2015

\section{References}

1. Peters DH, Bloom G. Developing world: bring order to unregulated health markets. Nature. 2012;487:163-5.

2. World Health Organization. Promoting rational use of medicines: core components. http://apps.who.int/medicinedocs/pdf/h3011e/h3011e.pdf] Accessed 1 Apr 2015.

3. Shankar PR, Partha P, Shenoy N. Self-medication and non-doctor prescription practices in Pokhara valley, Western Nepal: a questionnaire-based study. BMC Fam Pract. 2002;3:17.

4. Ernst E, Pittler MH. Risks associated with herbal medicinal products. Wien Med Wochenschr 1946. 2002:152:183-9.

5. Ernst E. Herbal medicines: balancing benefits and risks. Novartis Found Symp. 2007;282:154-67. discussion 167-172, 212-218.

6. Newton PN, Fernández FM, Plançon A, Mildenhall DC, Green MD, Ziyong L, et al. A collaborative epidemiological investigation into the criminal fake artesunate trade in South East Asia. PLoS Med. 2008;5:e32

7. Stein CM, Gora NP, Macheka BM. Self-medication in urban and rural Zimbabwean communities. Br J Clin Pharmacol. 1989:27:741-7.

8. Paphassarang C, Tomson G, Choprapawon C, Weerasuriya K. The Lao national drug policy: lessons along the journey. Lancet. 1995;345:433-5.

9. Stenson B, Syhakhang L, Eriksson B, Tomson G. Real world pharmacy: assessing the quality of private pharmacy practice in the Lao People's Democratic Republic. Soc Sci Med. 2001;52:393-404.

10. Sihavong A, Lundborg CS, Syhakhang L, Akkhavong K, Tomson G, Wahlström R. Antimicrobial self medication for reproductive tract infections in two provinces in Lao People's Democratic Republic. Sex Transm Infect. 2006:82:182-6

11. The World Bank. Out-of-pocket spending and health service utilization in Lao P.D.R. Evidence from the Lao expenditure and Consumption survey. http://documents.worldbank.org/curated/en/2010/11/13264669/outof-pocket-spending-health-service-utilization-lao-pdr-evidence-laoexpenditure-consumption-surveys. Accessed 1 Apr 2015.

12. Keohavong B, Syhakhang L, Sengaloundeth S, Nishimura A, Ito K. Rational use of drugs: prescribing and dispensing practices at public health facilities in Lao PDR. Pharmacoepidemiol Drug Saf. 2006;15:344-7.

13. Sengaloundeth $\mathrm{S}$, Green MD, Fernández FM, Manolin O, Phommavong K, Insixiengmay $V$, et al. A stratified random survey of the proportion of poor quality oral artesunate sold at medicine outlets in the Lao PDR - implications for therapeutic failure and drug resistance. Malar J. 2009:8:172.

14. Lao statistics bureau. Statistical yearbook. http://www.nsc.gov.la/en/PDF/ Final\%20Statistical\%20Year\%20book\%202012.pdf. Accessed 1 Apr 2015.

15. Mobillion V, Peyronnie K, Vallée J. L'offre de soins à Vientiane (RDP Lao): entre contrôle territorial et économie marchande. Space Popul Soc. 2006;2-3:341-9.

16. Syhakhang L, Freudenthal S, Tomson G, Wahlström R. Knowledge and perceptions of drug quality among drug sellers and consumers in Lao PDR. Health Policy Plan. 2004;19:391-401.

17. Levy PS, Lemeshow S. Systematic sampling. In: John Wiley and Sons, editor. Sampling of populations, methods and applications. 3rd ed. 1999.

18. Lao statistics bureau. Population census 2005.http://www.nsc.gov.la/en/PDF/ update\%20Population\%20\%202005.pdf. Accessed 1 Apr 2015.

19. Alvesson HM, Lindelow M, Khanthaphat B, Laflamme L. Coping with uncertainty during healthcare-seeking in Lao PDR. BMC Int Health Hum Rights. 2013;13:28

20. Alvesson HM, Lindelow M, Khanthaphat B, Laflamme L. Shaping healthcareseeking processes during fatal illness in resource-poor settings. A study in Lao PDR. BMC Health Serv Res. 2012;12:477.

21. Richards E, Theobald S, George A, Kim JC, Rudert C, Jehan K, et al. Going beyond the surface: gendered intra-household bargaining as a social determinant of child health and nutrition in low and middle income countries. Soc Sci Med. 2013;95:24-33.

22. Ministry of Planning and Investment, Department of Statistics. Poverty in Lao PDR 2008. [http://www.nsc.gov.la/en/PDF/Poverty\%20in\%20lao\%202008.pdf].

23. Ministry of Health, Food and Drug Department, Lao PDR. Statistics of medicine. http://www.fdd.gov.la/download/contents_documents/ 1408949867number_pharmacy_2013\%20by\%20districts.pdf. Accessed 1 Apr 2015.

24. Edwards $\mathbb{I R}$, Biriell C. Harmonisation in pharmacovigilance. Drug Saf. 1994;10:93-102.

25. Vidanapathirana J, Abramson MJ, Forbes A, Fairley C. Mass media interventions for promoting HIV testing. In: The Cochrane Collaboration, editor. Cochrane database of systematic reviews. Chichester: John Wiley \& Sons, Ltd; 2005.

26. Naugle DA, Hornik RC. Systematic review of the effectiveness of mass media interventions for child survival in low- and middle-income countries. J Health Commun. 2014;19 Suppl 1:190-215.

27. Syhakhang L, Lundborg CS, Lindgren B, Tomson G. The quality of drugs in private pharmacies in Lao PDR: a repeat study in 1997 and 1999. Pharm World Sci PWS. 2004;26:333-8.

28. Mekong Cartoon Contest. https://www.facebook.com/mekongcartooncontest. Accessed 1 Apr 2015

29. Syhakhang $L$. The quality of private pharmacy services in a Province of Lao PDR: perceptions, practices and regulatory enforcements. PhD thesis, Division of International Health (IHCAR), Department of Public Health Sciences. Stockholm: Karolinska Institutet; 2002.

30. Brounéus F, Macleod G, Maclennan K, Parkin L, Paul C. Drug safety awareness in New Zealand: public knowledge and preferred sources for information. J Prim Health Care. 2012:4:288-93

31. Shrank WH, Avorn J. Educating patients about their medications: the potential and limitations of written drug information. Health Aff Proj Hope. 2007:26:731-40

32. Dowse R, Barford K, Browne SH. Simple, illustrated medicines information improves ARV knowledge and patient self-efficacy in limited literacy South African HIV patients. AIDS Care. 2014;26:1400-6.

33. Minimum information for sensible use of self-prescribed medicines. An international consensus. Lancet. 1977;2:1017-19.

34. Lal A, Sethi A, Ray A. Informing patients about drugs. Natl Med J India. 1995:8:36-8. 
35. Morris LA, Halperin JA. Effects of written drug information on patient knowledge and compliance: a literature review. Am J Public Health. 1979;69:47-52.

36. Russell S. Treatment-seeking behaviour in urban Sri Lanka: trusting the state, trusting private providers. Soc Sci Med 1982. 2005;61:1396-407.

37. Riewpaiboon W, Chuengsatiansup K, Gilson L, Tangcharoensathien V. Private obstetric practice in a public hospital: mythical trust in obstetric care. Soc Sci Med. 2005:61:1408-17.

38. Gilson L. Editorial: building trust and value in health systems in low- and middle-income countries. Soc Sci Med. 2005;61:1381-4

39. WHO Programme Members. http://www.who-umc.org/DynPage.aspx? $i d=100653 \& \mathrm{mn} 1=7347 \& \mathrm{mn} 2 \% 20=7252 \& \mathrm{mn} 3=7322 \& \mathrm{mn} 4=7442$. Accessed 1 Apr 2015

40. Entezari-Maleki T, Taraz M, Javadi MR, Hajimiri MH, Eslami K, Karimzadeh I, et al. A two-year utilization of the pharmacist-operated drug information center in Iran. J Res Pharm Pract. 2014;3:117-22.

41. Melnyk PS, Shevchuk YM, Remillard AJ. Impact of the dial access drug information service on patient outcome. Ann Pharmacother. 2000;34:585-92.

42. Dodoo A, Hugman B. Risk perception and communication in sub-Saharan Africa. Drug Saf Int J Med Toxicol Drug Exp. 2012;35:1041-52.

43. Hien LTT, Takano T, Seino K, Ohnishi M, Nakamura K. Effectiveness of a capacity-building program for community leaders in a healthy living environment: a randomized community-based intervention in rural Vietnam. Health Promot Int. 2008;23:354-64.

44. Koenig SP, Léandre F, Farmer PE. Scaling-up HIV treatment programmes in resource-limited settings: the rural Haiti experience. AIDS Lond Engl. 2004;18 Suppl 3:S21-5.

45. Kaewkungwal J, Apidechkul T, Jandee K, Khamsiriwatchara A, Lawpoolsri S, Sawang $S$, et al. Application of mobile technology for improving expanded program on immunization among highland minority and stateless populations in Northern Thailand border. JMIR MHealth UHealth. 2015;3:e4

46. Baron S, Goutard F, Nguon K, Tarantola A. Use of a text message-based pharmacovigilance tool in Cambodia: pilot study. J Med Internet Res. 2013;15:e68.

\section{Submit your next manuscript to BioMed Central and take full advantage of:}

- Convenient online submission

- Thorough peer review

- No space constraints or color figure charges

- Immediate publication on acceptance

- Inclusion in PubMed, CAS, Scopus and Google Scholar

- Research which is freely available for redistribution 